\title{
Fuel Briquettes from Sal (Shorea robusta) Forest Litter as an Alternative Cooking Fuel
}

\author{
Sushmita Dulal ${ }^{1 *}$ and Ramesh Man Singh ${ }^{1}$ \\ ${ }^{1}$ Central Department of Environmental Science (CDES), ${ }^{2}$ Tribhuvan University, Centre Faculty CDES; Executive \\ Member, Centre for Energy and Environment Nepal (CEEN)
}

\section{*CORRESPONDENCE:}

Sushmita Dulal

Central Department of Environmental

Science (CDES), Tribhuvan University

Email: sushmitadulal@gmail.com

ISSN : 2382-5359(Online), 1994-1412(Print)

DOI:

https://doi.org/10.3126/njst.v20i1.39433

\section{ACCESS THE ARTICLE ONLINE}

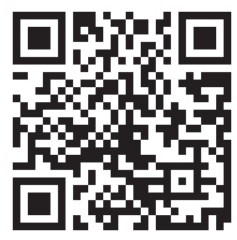

\section{CONFILICT OF INTEREST: None}

Copyright: The Author(s) 2020. This is an open access article under the $\mathbf{C C}$ BY license.

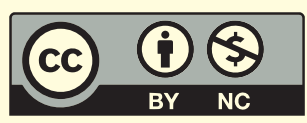

\begin{abstract}
Sal (Shorea robusta) forest leaf litter strongly influences seed germination and seedling survivorship. Therefore, it is crucial to open up the litter layer in such a forest with abundant leaf litter. Briquetting of Sal forest leaf litter can be an option for its management and meet the increasing energy demand. This research work is performed to quantify the amount of Sal forest litter and study the briquette's combustion properties. The study was carried out in the Namuna Community Forest of Jhapa district. The average weight of leaf litter in the field was observed to be $851 \mathrm{~g} / \mathrm{m}^{2}$. Five varieties of briquettes were produced using different briquetting technologies. Proximate analysis results, calorific value and water boiling tests show these briquettes have good fuel characteristics and can be used as alternative cooking fuel.
\end{abstract}

Keywords: Biobriquettes, pellets, calorific value, sal leaves.

\section{INTRODUCTION}

Nepal is heavily dependent on conventional emissive energy sources and imported fossil fuel for cooking purposes. At present, 73.5 percent of households rely on firewood and 34.9 per cent on LPG for cooking (World Bank 2019). Compared to firewood, LPG is a safer fuel because it does not produce smoke and degrade indoor air quality. However, as it is produced from fossil fuels, it contributes to global GHG emissions. In 2018-19, Nepal imported 429,609 MT of LPG, a rise of 270 per cent since 2008/09 (NOC 2019). This heavy dependence on LPG and other fossil fuel imports from neighboring countries has placed Nepal's energy supply system in a

vulnerable situation as seen during the blockade of 2015, when India's supply of fossil fuel to Nepal was severely disrupted. Thus, Nepal must reduce its reliance on imported fuel to improve its economy and shift the country towards locally available sustained energy.

Forest residue can play an efficient role to generate biomass energy. Sal forest shed leaves regularly between February to April, giving a thick bed of leaves litter (AEPC 2014). This accumulated leaf litter in the Sal forest may have several problems. Forest residue currently left in the forest to decay shares about $50 \%$ of the total forest biomass (Demirbas 2001). Methane, which has Global Warming Potential (GWP) of 28 (IPCC 2014), is produced during the natural decomposition process of biomass (Demirbas 2001). Although litter plays a significant role in vegetation development by adding nutrients to the soil, protecting seeds from predators, its adverse effects like a forest fire, forest regeneration problems and seedling survivorship generally outweigh the positive ones. Many experimental studies have shown that seedling survivorship and germination of seed are strongly affected by the litter quantity (Hughes et al. 1998). Therefore, in productive plant communities with abundant litter, activities and disturbances that open up the litter layer such as leaf litter collection should promote vegetation development (Xiong \& Nilsson 1999). 
Converting forest residue to biomass energy can be an alternative method to manage forest residue and recover the energy. Compared to other types of technology like gasification to recover energy, briquetting is simple, offers a whole range of technologies from small-scale production units to large-scale briquette plants (Singh 2010), and can be operated with moderately skilled labour. The low-cost method can be made at a village level to upgrade fuel, even using a hand-operated press. Moreover, biomass can be commercially harvested, and small village enterprises can be set up for briquette production, creating employment and generating income.

\section{MATERIALS AND METHODS}

\subsection{Study Area}

The study was carried out in Namuna Community Forest, which has 100 ha (Figure 1). It is about $4 \mathrm{~km}$ north from the Birtamode at Salbari, Sanischare Municipality of Jhapa District. It is located from N $26^{\circ} 40^{\prime} 37.4^{\prime \prime}$ to N $26^{\circ}$ 40'24.7' latitude, and E $88^{\circ} 00^{\prime} 37.6^{\prime \prime}$ to E $88^{\circ} 00^{\prime}$ '53.3" longitude. This study considered density of 9 species of trees including Shorea robusta in aligned with the study of Bhattarai 2008 (Bhattarai 2008). Among these species, our study was focused on leaf litter of Shorea robusta only.

\subsection{Quantification of Sal Litter}

Quantification of Sal forest leaf litter was carried out by using simple random sampling. 100 optimum number of sampling plots were calculated by using $0.01 \%$ sampling intensity. Sampling plots along the selected area were located using Arc GIS 10.2. GPS was used to locate the plot's position, and a quadrat of $1 \times 1 \mathrm{~m}^{2}$ was laid. All the leaf litters within the quadrates were collected, weighed and noted. Finally, the average weight was taken.

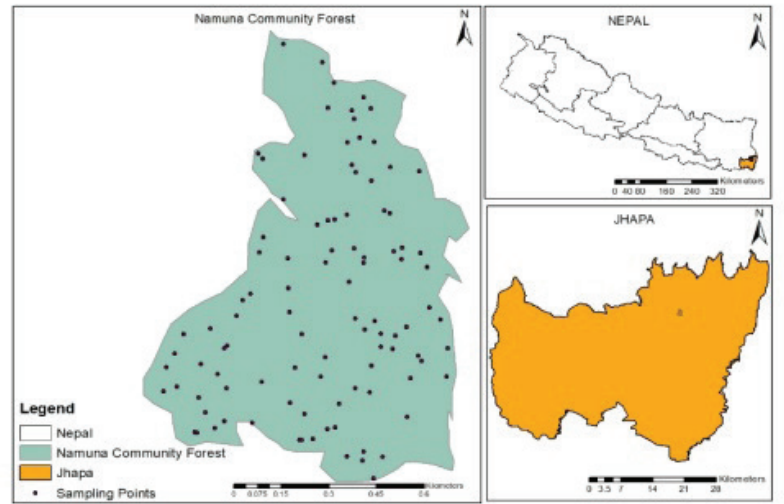

Leaf litter from Sal forest was collected as the raw material for making briquettes. These raw materials were sundried to reduce moisture and then screened to remove the impurities. Part of the dried raw material was ground to powder form to make brown briquettes, and the rest was used to make charcoal using a charring drum.

\subsection{Briquette Production}

Both brown briquettes and carbonized (black) briquettes were produced. Three types of brown briquettes were produced, i.e. in low compaction (using paper as a binder) and under high pressure using the screw extruder briquetting machine. Two kinds of low compaction briquette were produced using different Sal powder and Paper ratios, i.e. (Sal + paper, 70: 30 and Sal + paper, 50: $50)$.

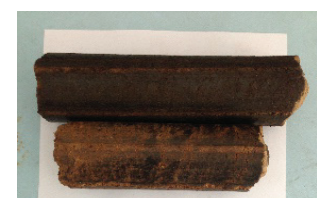

Figure2: High compaction brown briquettes

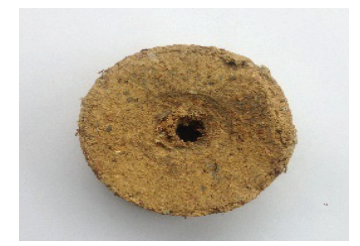

Figure 4: Brown briquette ( $50 \%$ leaf litter $+50 \%$ paper)

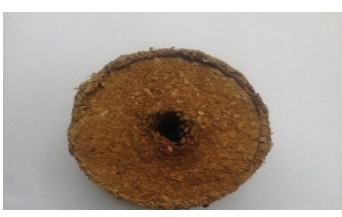

Figure3: Brown briquette ( $70 \%$ leaf litter $+30 \%$ paper $)$

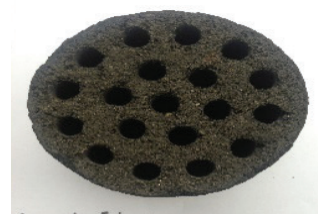

Figure 5: Black briquette $(60 \%$ Sal leaf char $+40 \%$ clay $)$

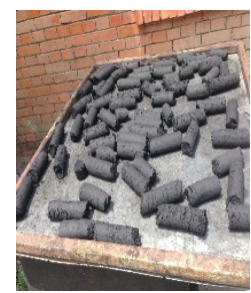

Figure 6: Black briquette charcoal pellets with $\mathrm{CMC}$ binder

Beehive briquette and Pellets were produced using clay and Carboxymethylcellulose (CMC) as binders, respectively. High compaction binder less brown briquettes were produced using screw extruder technology with heated die at $300^{\circ} \mathrm{C}$ temperature.

Table 1: Composition of different kinds of Briquette Fuel sample

\begin{tabular}{|c|c|c|c|c|c|}
\hline Materials & S1 & $\underline{\mathrm{S}} 2$ & $\underline{\mathrm{S} 3}$ & $\underline{\mathrm{S}} 4$ & $\underline{\mathrm{S} 5}$ \\
\hline Sal leaves & $100 \%$ & $70 \%$ & $50 \%$ & & \\
\hline Sal leaves char & & & & $60 \%$ & $90 \%$ \\
\hline Paper & & $30 \%$ & $50 \%$ & & \\
\hline Clay & & & & $40 \%$ & \\
\hline $\mathrm{CMC}$ & & & & & $10 \%$ \\
\hline
\end{tabular}

(Note: S1-Screw extruder briquette, S2-Sal + Paper (70:30), S3-Sal + Paper (50:50), S4-Beehive briquette, S5-Charcoal Pellets) 


\section{FUEL CHARACTERISTICS AND WBT}

\subsection{Proximate Analysis and Calorific Value}

Proximate analysis was carried following the Japanese Industrial Standard (JIS, 8812) using a Drying oven and Muffle furnace (Carbolite Muffle Furnace AAF 11/7). The calorific value of the different biomass and briquettes was determined using Toshniwal Digital Bomb Calorimeter.

\subsection{Water Boiling Test (WBT)}

The briquettes' combustion tests produced from Sal forest litter were carried out using the modified Water Boiling Test (Water Boiling Test version 4.2.4) using Agni stove introduced by CEEN. Test using other type of stoves was beyond the scope of this work due to time constraints. During this test, fuel characteristics like thermal efficiency, specific fuel consumption, boiling time, ignition time and the burning rate was calculated. Besides, Carbon monoxide (CO) emission tests from the combustion of fuel were also performed. $\mathrm{CO}$ emission was measured using a Fluke $\mathrm{CO}$ meter as described in Water Boiling Test Version 4.2.4. The instrument was kept one and a half meter above the ground and one meter to the side of the stove. It gives the automatic reading of concentration of $\mathrm{CO}$ emission in ppm (parts per million). CO concentration was measured after the ignition of briquettes at the interval of every minute during the boiling period.

\section{RESULTS AND DISCUSSION}

\subsection{Leaf Litter Characteristics}

The average weight of leaf litter in the study area was found to be $851 \mathrm{~g} / \mathrm{m}^{2}$. Generally, litter in the range of 100 to $300 \mathrm{~g} / \mathrm{m}^{2}$ increases yield and diversity, virtually by conserving the soil moisture. Likewise, litter amount between 300 and $900 \mathrm{~g} / \mathrm{m}^{2}$ affects plant diversity and density while litter above $900 \mathrm{~g} / \mathrm{m}^{2}$ decrease productivity, diversity and plant reproduction (Carson \& Peterson1990). This generalization may not be accurate in all the plant communities, as species will respond individually to the litter quantity. However, they may be approximate indicators regarding litter's potential impacts in the plant community (Carson \& Peterson 1990).

A study has shown that out of 3,654 million ha of forest area accessible for improved management, Sal forest occupies an area of 1,320,000 ha in Nepal (Ojha et al.2008). From this study, we got to know that the total litter fall in the study area during the fall season may reach up to 851 tons/ ha. Taking this as a reference, and the Sal forest area of Nepal as 1,320,000 ha (Acharya et al. 2017), leaf litter quantity around $1,123,320,000$ tons of leaf litter will be available. The various literature recommends that litter more than $300 \mathrm{~g} / \mathrm{m}^{2}$ be timely disposed of for better forest management. Considering this figure, the average amount of litter available for utilization is about $551 \mathrm{~g} / \mathrm{m}^{2}$. Thus, the total amount of leaf litter available for utilization in the study area is about 551 tons/ha. Multiplying this with the total area occupied by Sal forest in Nepal, i.e. 1,320,000 ha, around 727,320,000 tons of leaf litter will be available.

\subsection{Proximate Analysis of Fuel}

Results of the proximate analysis of biomass and briquette samplesproducedare presented in Table 2.

Table 2: Results of Proximate analysis of biomass and fuel samples

\begin{tabular}{|l|c|c|c|c|}
\hline $\begin{array}{l}\text { Biomass and Fuel } \\
\text { sample }\end{array}$ & $\begin{array}{c}\text { Moisture } \\
\text { content } \\
(\%)\end{array}$ & $\begin{array}{c}\text { Volatile matter } \\
\text { content (\%) }\end{array}$ & $\begin{array}{c}\text { Ash content } \\
(\%)\end{array}$ & $\begin{array}{c}\text { Fixed } \\
\text { carbon } \\
\text { content } \\
(\%)\end{array}$ \\
\hline Sal leaves & 8.53 & 69.43 & 6.77 & 15.25 \\
\hline Sal char & 5.15 & 26.45 & 9.45 & 58.93 \\
\hline Paper & 7.14 & 75.26 & 9.59 & 7.98 \\
\hline $\begin{array}{l}\text { Screw extruder } \\
\text { briquette }\end{array}$ & 4.24 & 71.74 & 6.44 & 17.55 \\
\hline Beehive briquette & 3.20 & 19.43 & 49.21 & 28.14 \\
\hline Sal + Paper (50:50) & 8.77 & 72.64 & 8.60 & 9.96 \\
\hline Sal +Paper (70:30) & 8.57 & 70.37 & 8.39 & 12.65 \\
\hline Pellet & 5.26 & 24.86 & 17.51 & 52.35 \\
\hline
\end{tabular}

The moisture content of the Sal leaves was found to be $8.5 \%$. This value lies within the suitable working moisture content of $8-12 \%$ (Eriksson \& Prior 1990) or can be up to 15\% (Grover \& Mishra 1996) for making briquette. Most biomass has a moisture fraction of up to $60 \%$ (Mukunda 2009). The paper's moisture content in the present study is $7.14 \%$, which is quite higher than the value obtained, i.e. 3.1 to $4.3 \%$ moisture content of the mixed paper (Kalanatarifard \& Yang 2012). Sal leaves char (5.15\%) ' moisture content was less than that of the Sal leaves $(8.53 \%)$. The reduction of moisture content is probably due to the heating process during carbonization. Screw extruder briquette has lower moisture content $(4.25 \%)$ than other brown briquettes because the raw material has been processed under high temperature $\left(\sim 300^{\circ} \mathrm{C}\right)$.

The volatile matter content of the biomass and fuel sample varied from $19.43 \%$ to $75.26 \%$. In a good quality of biomass briquette, high volatile matter content of around $70 \%$ to $86 \%$ is present (KB \& Jnanesh 2015). Sal leaves briquette, contains volatile content of nearly $70 \%$, which indicates the easy ignition of the briquette. The char $(26.45 \%)$ volatile matter was much lower than that of the Sal leaves $(69.43 \%)$. Paper has the highest volatile matter content $(75.26 \%)$ than other biomass and fuel sample. Higher volatile matter in briquette with $50 \%$ paper binder seems evident as it contains two highly volatile matters, i.e. paper and Sal leaves.

Ash content of the biomass and fuel sample varied from $6.44 \%$ to $49.21 \%$. The Ash content of Sal leaves char $(9.45 \%)$ was higher than those of Sal leaves $(6.77 \%)$. It implies that during carbonization, most of the ash in biomass remained in char. In general, biomass residues have lower ash content except rice husk with about $20 \%$ ash (Singh 2010). The Ash content of the paper was found 
to be $9.59 \%$. This value is similar to the $9 \%$ ash content of paper (Kalanatarifard \& Yang 2012). The Ash content of the Screw extruder briquette $(6.44 \%)$ is lower than that of other low compaction brown briquettes. They contain paper with higher ash content $(9.59 \%)$ as a binder in different proportions, i.e. $30 \%$ and $50 \%$. Among the fuel samples prepared, beehive briquette had the highest ash content (49.21\%). It must be from the mixing of $40 \%$ clay binder with Sal char during briquetting. Higher ash content usually leads to a lower calorific value of fuel, while low ash content makes it suitable for thermal utilization (Koppejan \& Loo 2008).

Fixed carbon content gives a rough estimation of heating value and acts as the primary heat generator during burning. The low fixed carbon content releases low heat and tends to prolong cooking time (Efomah \& Gbabo 2015). Considering the fixed carbon content, the best quality of fuel sample produced was charcoal pellet (52\%) followed by beehive $(28.14 \%)$ and screw extruder briquette $(17.55 \%)$. The fixed carbon content of briquette with $50 \%$ and $30 \%$ paper binder are almost similar. The fixed carbon content of Sal leaves char $(58.93 \%)$ is higher than other raw biomass, i.e. Mikania micrantha char (45.921\%) (Pandey \& Regmi 2013) indicating the excellent quality of Sal leaf as biomass available for briquette. Sal leaf charcoal had $58.93 \%$ of fixed carbon, which lies in the range (50-95\%) set by(FAO 1985). The fixed carbon content of Sal leaves $(15.25 \%)$ is similar to that of Eupatorium adenophorum(15.27\%) and higher than that of water hyacinth (3.65) and rice straw (12.67\%) (Pandey \& Regmi 2013). The fixed carbon content of the waste paper in the present study is $7.98 \%$. This value is similar to the $7 \%$ fixed carbon of paper (Kalanatarifard \& Yang 2012).

\subsection{Calorific Value of Biomass and Fuel Sample}

The Calorific value of different biomass materials and briquette samples is presented in Table 3.

Table 3: Calorific value of biomass and fuel sample

\begin{tabular}{|l|l|}
\hline Biomass and Fuel sample & Calorific value (kJ/kg) \\
\hline Sal leaves & $19,128.96$ \\
\hline Sal leaves Char & $26,594.59$ \\
\hline Paper & $15,323.86$ \\
\hline Screw extruder (S1) & $20,763.06$ \\
\hline Sal + Paper (70 : 30) (S2) & $17,537.45$ \\
\hline Sal + Paper (50: 50) (S3) & $16,794.44$ \\
\hline Beehive (S4) & $13,449.26$ \\
\hline Pellet (S5) & $23,242.16$ \\
\hline
\end{tabular}

Calorific value is the essential property of fuel and determines its energy content. The calorific value of biomass and fuel samples varied from 15,323.86 to $26,594.59 \mathrm{~kJ} / \mathrm{kg}$. Sal leaves calorific value was found to be $19,128.96 \mathrm{~kJ} / \mathrm{kg}$, which seems to be higher compared to Areca leaves, which were found to be $13,025 \mathrm{~kJ} / \mathrm{kg}$ (KB \& Jnanesh 2015). The screw briquette made from $100 \%$ Sal leaves had a higher calorific value $(20,763.06 \mathrm{~kJ} / \mathrm{kg})$ than the Sal leaf litter. It is because a thin layer of char is formed on the briquette surface during briquetting. It is also reported that the calorific value of fuel briquettes increases with the increase in temperature as it reduces the moisture content of the fuel while increasing the fixed carbon concentration (Supatata et al. 2013). Thus, the increase in the calorific value is partly attributed to the slight difference in the materials' moisture content; as at the time of the analyses, Sal leaf litter had a moisture content of $8.54 \%$ while screw extruder briquettes had a moisture content of $4.25 \%$. Also, the energy content of the screw extruder briquette $(20,763.06 \mathrm{~kJ} / \mathrm{kg})$ is higher than other low compression brown briquettes $(17,537.45 \mathrm{~kJ} /$ $\mathrm{kg}$ and $16,794.44 \mathrm{~kJ} / \mathrm{kg}$ ) with $30 \%$ and $50 \%$ paper binder respectively. It might be because of the lower moisture content, i.e. $4.24 \%$ and higher fixed carbon content, i.e. $17.55 \%$. Also, the low compression brown briquettes contain paper as a binder, which has a lower energy value than the Sal leaves. It might be the reason for the lower calorific value of the low compression briquettes.

The calorific value of Sal leaves char $(26,594.59 \mathrm{~kJ} / \mathrm{kg})$ was found to be higher than Sal leaves $(19,128.86 \mathrm{~kJ} / \mathrm{kg})$. It might be because of the lower moisture content, i.e. $5.15 \%$ and higher fixed carbon content, i.e. 58.93\% compared to Sal leaves. During the carbonization process, emission of surface moisture and volatile matter occurs, resulting in the charred biomass's higher fixed carbon content. In black briquettes, beehive has a lower calorific value $(13,449.26 \mathrm{~kJ} / \mathrm{kg})$ as compared to pellets $(23,242.16 \mathrm{~kJ} /$ $\mathrm{kg})$. It is because of the higher ash content (49.21\%) which comes from the clay binder. Ash is the non-combustible component of the fuel, and calorific value decreases with a higher ash content of the Fuel (Koppejan \& Loo 2008).

\subsection{Water Boiling Test}

The water-boiling test was performed to see the thermal efficiency of different fuels and briquettes' performance as an alternative to fuel wood determining other fuel properties like flame temperature, ignition time, water boiling time and burning rate of the fuel.

The efficiency of the stove was highest at $35.90 \%$ when operated with beehive briquette. The beehive briquette has 19 holes in it altogether. The blue flames from each of the holes are focused on the pot, which might be the reason for higher efficiency. Screw extruder briquettes and briquettes bonded with $30 \%$ and $50 \%$ paper binder show similar thermal efficiency, i.e. $26.302 \%, 28.43 \%$ and $27.285 \%$, respectively. Pellet had the least cooking efficiency (22\%). It might be because pellet burns slowly, and the height of flames was lower than other fuels. Therefore, it took the longest time to boil the water and much quantity (350 g) needed to boil the water. The stove was not compatible with the fuel, as the flame was not reaching the pot. The 
thermal efficiency of the fuel samples is given in Table 4.

Table 4: Thermal efficiency of fuel samples

\begin{tabular}{|l|l|l|}
\hline SN. & Briquette fuel samples & Thermal efficiency (\%) \\
\hline 1 & Screw extruder & 26.72 \\
\hline 2 & Beehive & 35.90 \\
\hline 3 & Sal +Paper (70:30) & 27.29 \\
\hline 4 & Sal+Paper (50: 50$)$ & 28.43 \\
\hline 5 & Pellet & 22.71 \\
\hline
\end{tabular}

The brown briquettes' flame temperature is higher (ranging from $600-700^{\circ} \mathrm{C}$ ) more than for the black briquettes that range upto $410^{\circ} \mathrm{C}$. Brown briquettes have higher volatile content than the black briquettes shown by the proximate analysis (Table 2). In volatile combustion, the flame is higher than the char combustion. Therefore, the higher temperature is recorded for all brown briquettes. However, for the combustion of the same quantity of briquettes, the period of combustion of black (charcoal) briquettes are two times ( $>60$ mins) that of brown (biomass) briquettes ( $\sim 30$ mins). Figure 7 shows the fuel combustion profile (flame temperature and combustion period) of selected fuel briquettes samples.

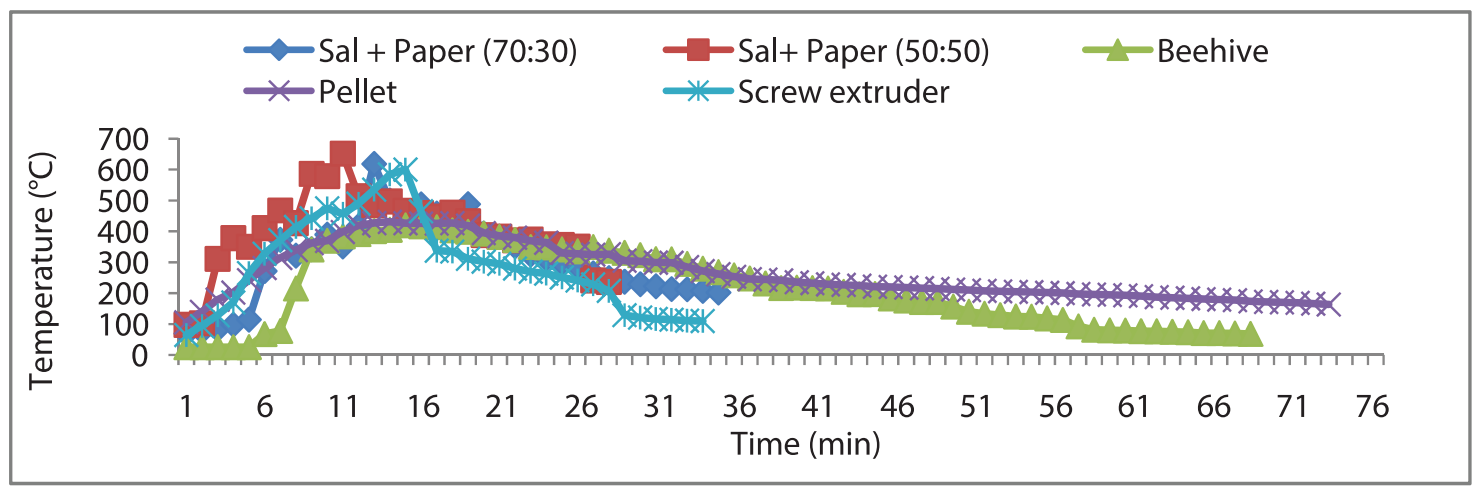

Fig.7. Flame temperature profile of the fuel

\subsection{Ignition Time, Burning Rate, Density and Specific Fuel Consumption}

The Ignition Time, Burning Rate, Density and Specific fuel consumption of the fuel sample are shown in Table 5.The ignition time of the briquettes shows that brown briquettes are easily ignited, unlike charcoal briquettes. The increase in the ignition time in screw briquette could be attributed to increased density due to better binding, resulting in low porosity hence reduced infiltration of oxygen.

While in the case of black fuel, the pellet took more time to ignite than beehive briquette. The pellet's density is higher than that of the beehive briquette, which might have resulted in low porosity. Beehive briquette being porous might have allowed easy infiltration of oxygen contributing to the faster ignition.

The burning rate of the pellet was low compared to other fuel, which might be the reason for the fuel's lower efficiency. This result indicates that not only calorific value but also the burning rate is equally important to factor controlling efficiency.

Briquettes produced using screw extruder technology has a higher density of $1.018 \mathrm{~g} / \mathrm{cm}^{3}$. This technology uses a tapered die, which gives products with more excellent compaction.
Table 5: Ignition Time, Burning Rate, Density and Specific fuel consumption of fuel samples

\begin{tabular}{|l|l|l|l|l|l|}
\hline SN & Sample & $\begin{array}{l}\text { Ignition } \\
\text { time }(\mathrm{min})\end{array}$ & $\begin{array}{l}\text { Burning } \\
\text { rate }\end{array}$ & $\begin{array}{l}\text { Density }(\mathrm{gm} / \\
\left.\mathrm{cm}^{3}\right)\end{array}$ & $\begin{array}{l}\text { Specific fuel } \\
\text { Consumption }\end{array}$ \\
\hline 1 & $\begin{array}{l}\text { Screw } \\
\text { extruder }\end{array}$ & 6 & 8.13 & 1.018 & 0.7125 \\
\hline 2 & $\begin{array}{l}\text { Sal + Paper } \\
(70: 30)\end{array}$ & 2 & 9.63 & 0.289 & 1.059 \\
\hline 3 & $\begin{array}{l}\text { Sal + Paper } \\
(50: 50)\end{array}$ & 1 & 9.28 & 0.357 & 0.92 \\
\hline 4 & Beehive & 7 & 5.33 & 0.336 & 0.7905 \\
\hline 5 & Pellet & 11 & 5 & 0.600 & 0.628 \\
\hline
\end{tabular}

\subsection{CO emission}

The average $\mathrm{CO}$ concentrations during the different combustion phase for different fuel samples are shown in Figure 8 . The emissions were observed as high as $88 \mathrm{ppm}$ for pellets during combustion (Figure 8).

Emission from beehive briquette was found comparatively lower than the other fuel sample. It might be due to the higher efficiency of the beehive briquette with the stove. Moreover, the emission from the pellet was found to be higher than other fuel. As emission from biomass depends on the cooking stoves' operation in a variety of designs (Petrocelli \& Lezzi 2014), the higher emission also might be due to the lower efficiency of the stove with pellet. $\mathrm{CO}$ is released because of the incomplete combustion of volatiles in the flaming phase or from the combustion of char during 
the smoldering phase (Petrocelli \& Lezzi 2014). Also, CO production is positively affected by the excess air and its distribution. When the air supply is abundant, (the air-fuel ratio is high) $\mathrm{CO}$ is low as $\mathrm{CO}$ changes to $\mathrm{CO}_{2}$. Thus, to minimize the $\mathrm{CO}$ emission, it is essential to function in the optimal interval of excess air.

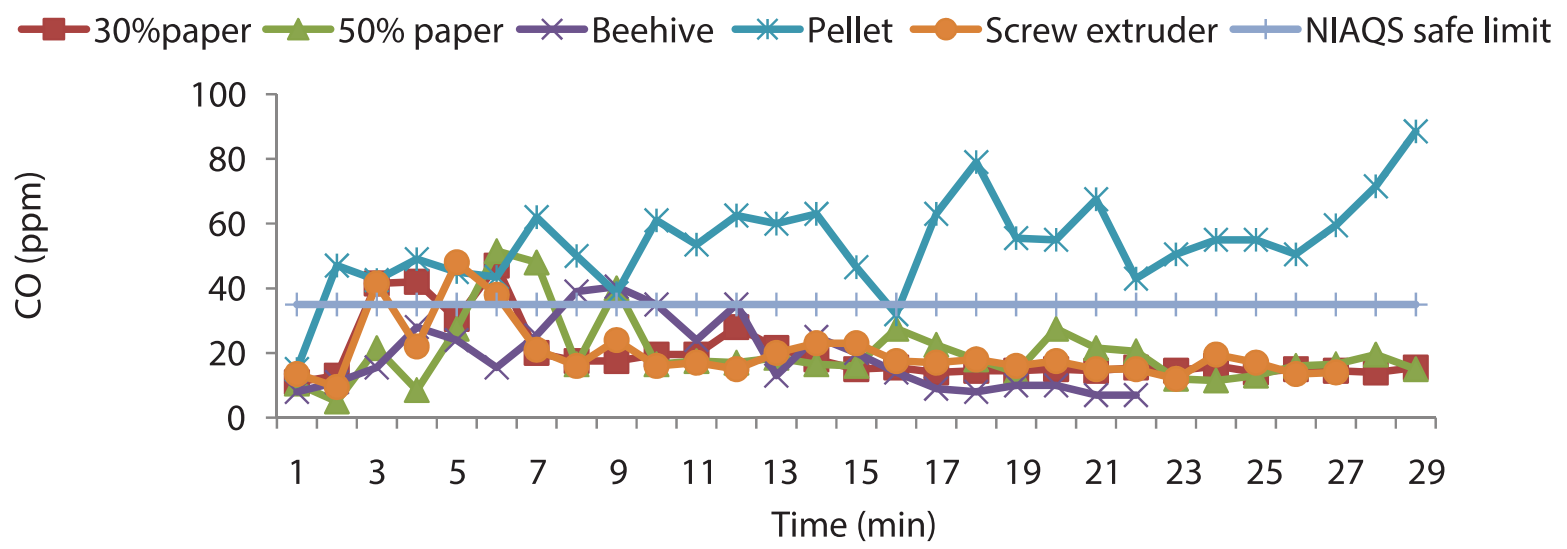

Fig. 8. CO emission of fuel sample

\section{CONCLUSION}

Sal forest leaf litter briquetting can be a wise management option of forest residues. It also helps in addressing the growing energy demand of Nepal. The following conclusions can be drawn from the study:

The average weight of leaf litter in the study area was observed to be $851 \mathrm{~g} / \mathrm{m}^{2}$ which can be used to quantify Sal forest leaf litter in similar forest areas of Nepal. The quantification of leaf litter demonstrates the vast potential of it as an alternative fuel for energy generation.

Altogether five varieties of low and high-density briquettes (brown and black) were produced using different binders and various briquetting technologies. The density of briquettes increased with the increasing amount of paper binder in the pulp briquetting process. Among the three binders used, i.e. CMC, paper, and clay, CMC showed a better binding effect.

Based on the proximate analysis, screw extruder briquettes, low compaction briquettes, beehive briquettes, and charcoal pellets showed good fuel properties and good potential to be used as an alternative fuel. Beehive briquette also shows good potential for cooking as it has the highest thermal efficiency when operated with an Agni stove. The fuel properties determined in this study suggest that briquettes from Sal leaf litter have good fuel properties and can be used as an alternative to fuel wood for heating and cooking purposes.

\section{ACKNOWLEDGEMENT}

We would like to thank the Central Department of Environmental Science (CDES) for providing a research grant and the Centre for Energy and Environment Nepal (CEEN) for providing laboratory. We would also like to thank Ms. Anju Pokharel, Mr. Laba KC and Mr. Nabin Bhandari for their help during the lab work.

\section{REFERENCES}

1. Acharya, K.P., P.R. Tamrakar, G. Gautam, R. Regmi, A. Adhikari and B. Acharya 2017. Managing tropical Sal forests (Shorea robusta) in Nepal in short rotations: findings of a 12-year long research. Banko Janakari, 12(1), 71-75.

2. AEPC. 2014. Final Report for Study on Feasibility and Market Identification of Densified Biomass Briquettes. Kathmandu Nepal: Alternative Energy Promotion Centre.

3. Bhattarai, K.P. 2008. Vegetation analysis of Namuna Community Forest of Salbari, Sanischare VDC in Jhapa District, Eastern Nepal. Journal of Natural History Museum, 12-15.

4. Carson, W.P. and C.J. Peterson 1990. The role of litter in an old-field community: impact of litter quantity in different seasons on plant species richness and abundance. Oecologia, 8-13.

5. Demirbas, A. 2001. Biomass resource facilities and biomass conversion processing for fuels and chemicals. Energy Conversion and Management, 1357-1378.

6. Efomah, A.N. and A. Gbabo. 2015. The physical, Proximate and Ultimate Analysis of Rice Husk Briquettes Produced from a vibratory Block Mould Briquetting Machine. International Journal of Innovative Science, Engineering \& Technology.

7. Eriksson, S. and M. Prior. 1990. The briquetting of agricultural wastes for fuel. Bangkok.: Food and Agriculture Organization of the United Nations.

8. FAO. 1985. Industrial Charcoal Making. Rome, Italy: Food and Agriculture Organization of the United Nations. 
9. GBEP. 2007. A review of the current state of bioenergy development in G8+ 5 countries. Rome: Global bioenergy Partnership Secretariat, Food, and Agriculture Organization of the United Nations (FAO).

10. Grover, P. and S. Mishra. 1996. Biomass briquetting: technology and practices. Bangkok: FAO Regional Wood Energy Development Programme.

11. Hughes, F.K., T.P. Young and M.M. Carreiro. 1998. Forest leaf litter quantity and seedling occurrence along an urban-rural gradient. Urban Ecosystems, 263278.

12. IPCC. 2014. Climate Change 2014: Synthesis Report. Contribution of Working Groups I, II and III to the Fifth Assessment Report of the Intergovernmental panel on Climate Change.Geneva, Switzerland: IPCC.

13. K.B, D. and N. Jnanesh. 2015. Investigation of Areca Leaves as a Biomass Fuel by the Method of Briquetting. IPASJ International Journal of Mechanical Engineering (IIJME).

14. Kalanatarifard, A. and G.S. Yang. 2012. Identification of the municipal solid waste characteristics and potential of plastic recovery at Bakri Landfill, Muar, Malaysia. Journal of Sustainable Development.

15. Koppejan, J. and S.v. Loo. 2008. The Handbook of Biomass Combustion and Co-firing. London: Routledge.

16. Mukunda, H. 2009. Understanding combustion. Hyderabad, India: Universities Press (India) Private Limited,

17. NOC. 2019. Import and Sales. Retrieved from Nepal Oil Corporation Limited: http://noc.org.np/import

18. Ojha, S.K., K. Acharya, B. Acharya and R. Regmi. 2008. Simple coppice management options for the
Sal (Shorea robusta Gaertn. f.) forests in the Terai of Nepal. Banko Jhankri, 32-41.

19. Pandey, S. and C. Regmi. 2013. Analysis and test of biomass briquette and stoves. Nepal. Journal of Science and Technology, 115-120.

20. Petrocelli, D. and A. Lezzi. 2014. CO and NO emissions from pellet stoves: an experimental study. Journal of Physics.

21. Shrestha, A. and R.M. Singh. 2012. Energy Recovery from Municipal Solid Waste by Briquetting Process: Evaluation of Physical and Combustion Properties of the Fuel. Nepal Journal of Science and Technology, 12(Volume 12 (2011) ), 238-241.

22. Singh, R.M. 2010. Development of Report on National Policy Recommendation for the promotion of bio briquette technology in Nepal. Kathmandu Nepal: National Alternative Energy and Engineering Service.

23. Supatata, N., J. Buates and P. Hariyanont. 2013. Characterization of Fuel Briquettes Made from Sewage Sludge Mixed with Water Hyacinth and Sewage Sludge Mixed with Sedge. International Journal of Environmental Science and Development, 179-181.

24. WECS. 2010. Energy Sector Synopsis Report 2010. Kathmandu, Nepal.: Water and Energy Commission Secretariat.

25. World Bank. 2019. NEPAL | Beyond Connections: Energy Access Diagnostic Report Based on the MultiTier Framework. World Bank.

26. Xiong, S. and C. Nilsson. 1999. The Effects of Plant Litter on Vegetation: A Meta-Analysis. Journal of Ecology, 984-994. 